\section{Centre for Evidence-based Medicine website gets revamp}

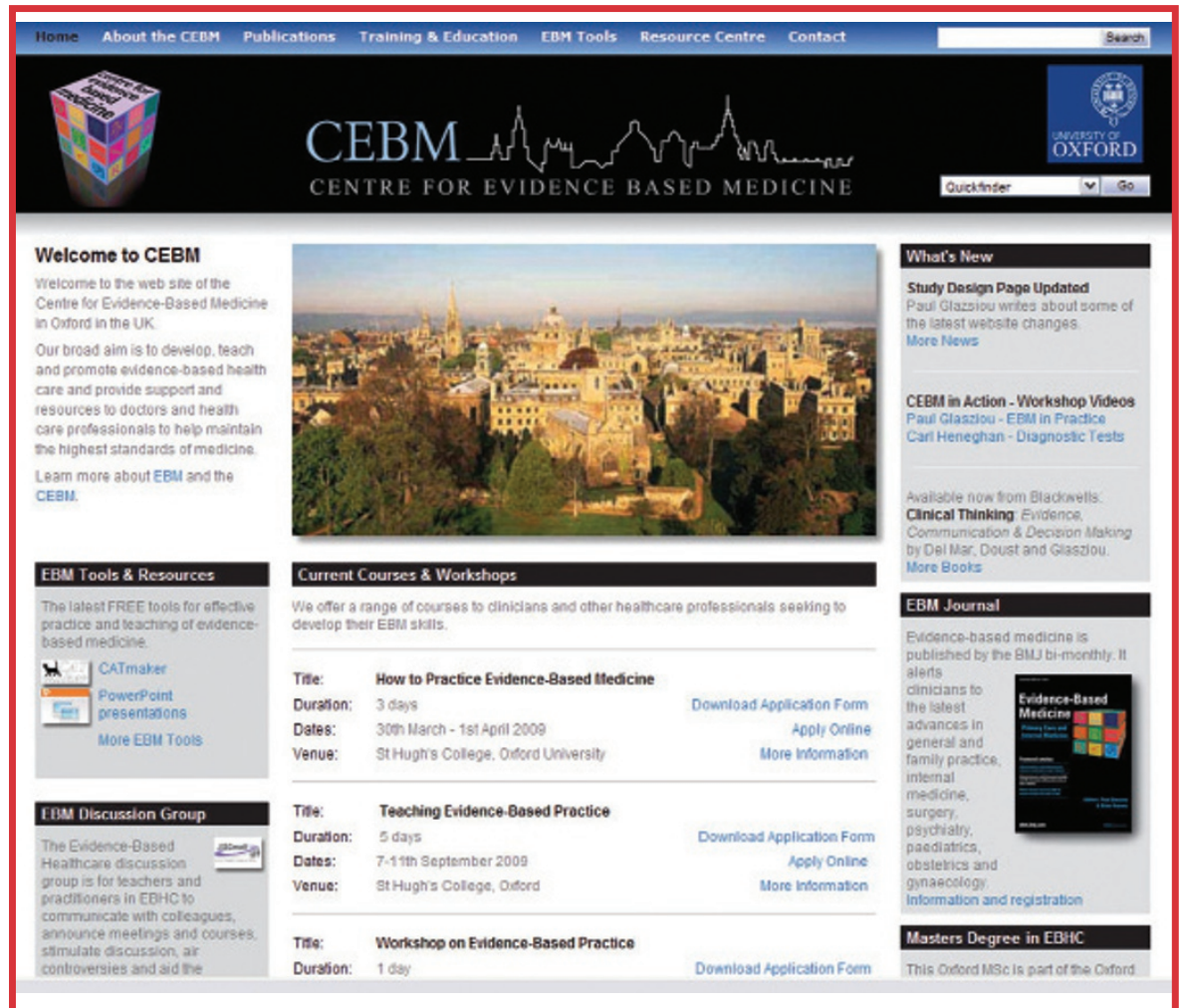

Figure 1. Centre for Evidence-based Medicine homepage

The Centre for Evidence-based Medicine (CEBM) website (www.cebm.net) has just received a major overhaul. The Oxford centre was established as the first of several UK centres that aimed to promote evidencebased healthcare. The CEBM has been helpful in the establishment and maintenance of the Centre for Evidence-based Dentistry (www.cebd.org), also based in Oxford.

The new website has a attractive, fresh and clean look and contains many of the old favourites such as the CATmaker, a software tool for creating critically appraised topics, critical appraisal sheets, calculators for $2 \times 2$ tables, likelihood ratios and confidence intervals. The quick finder box is a very useful way of finding these old friends, particularly the levels-of-evidence table. The new website has a couple of short videos and an increasing number of PowerPoint (Microsoft, Redmond, Washington, USA) presentations to help people practise and teach evidence-based healthcare. It is great to see how the Centre has developed in recent times and their new website is well worth bookmarking if you are at all interested in evidence-based healthcare.

\section{NHS evidence}

One of the recommendations of the Darzi report ${ }^{1}$ was for the UK National Institute for Health and Clinical Excellence to establish 'NHS Evidence'. NHS Evidence will be a web-based service to help people find, access and use high-quality clinical and nonclinical evidence and best practice. The development of NHS Evidence is likely to see the National Library of Health (www.library.nhs.uk) brand disappear.

It is planned that the NHS Evidence website will launch in April 2009. The website will be built around a number of clear principles:

- clinical and professional networks are involved at all stages;

- comprehensive access to a variety of information sources;

- service is straightforward and easy to use;

- key sources of information are highlighted as trusted sources through an independent accreditation service;

- access to primary research, including clinical trials;

- service is designed around the needs of NHS staff and other relevant professionals.

The NHS Evidence accreditation process will quality-assess guidance producers to help users to recognise high quality information sources.

The draft accreditation process (http:// www.nice.org.uk/aboutnice/nhsevidence/ NHSEvidenceAccreditationProcessManual Consultation.jsp) is out for public consultation until 1 May 2009.

1. Professor the Lord Darzi of Denham KBE. High Quality Care For All. NHS Next Stage Review Final Report. Crown Copyright 2008. 